officers and the subject be properly taught to students. The third should be to make a thorough course of instruction in anæsthetics a necessary part of the medical education of every legally qualified medical practioner, so that before administering anæsthetics on his own responsibility he would have administered a large number under the supervision of a competent teacher. There is ample material, not only in our general but in our special hospitals, for the most thorough practical instruction of all our medical students. The fourth reform needed is the registration by all hospitals of all anæesthetics administered, so that it may be possible, at all events as regards such institutions, to ascertain the death-rates of the different agents employed and to watch the effects of any reforms that may be introduced.

If such changes as these were effected the public would undoubtedly be protected as far as is possible against deaths under anæsthetics, for they would have at their disposal throughout the country qualified and thoroughly trained practitioners who would realise the responsibilities intrusted to them. Moreover, in our provincial towns and other centres throughout the country there would always be available numerous practitioners who, as the result of the improved hospital equipment, had held resident or non-resident anæsthetic offices. Such specially qualified practitioners, whilst practising as surgeons, physicians, or general practitioners, would be of incalculable value in surgical and in dental practice. It is in the highest degree probable that under such a régime deaths during anæsthesia would rapidly decline in number, and that the discreditable incidents now too often associated with the giving of anæsthetics for surgical and dental operations would become a thing of the past. It is a matter for great congratulation that the General Medical Council has lately looked farourably upon the more important of the above-mentioned reforms, and it is to be hoped that ere long legislation may be granted in the directions indicated.

Queen Anne-street, $W$.

\section{A CASE OF FRACTURE OF THE RIBS, RUPTURE OF THE LUNG, AND PNEUMOHÆMOTHORAX,}

WITH NOTES OF THE POST-MORTEM EXAMINATION.

By MARY O. DE GARIS, M.D., B.S. MELB.,

RESIDENT SURGEON AT THE MUTTABURRA HOSPITAL, QUEENSLAND.

A BUshman, aged 50 years, was admitted to the Mutta burra Hospital on August 11th, 1907. He stated that on the preceding Thursday (the 8th) he was thrown by his horse, which then rolled on him. He was alone with nothing to eat or drink but some tea until he was brought into the hospital. He said that he coughed up a large amount of blood after the accident, that he passed blood with his urine, and that his bowels had not been opened.

On examination there were several bruises on the back of the shoulders. His head was bent forward and his neck could not be straightened without pain. There was an ecchymosis below the right eye. His right arm hung helpless at his side, both passive and active movement being very limited; the humeral head was in normal position, but the acromion process was very prominent, and there was apparent crepitus on passive movement of the shoulder. There was no swelling about the shoulder. The clavicle, acromion, and forearm bones were all sound. The abdomen showed no abnormal signs. His temperature was $101^{\circ} \mathrm{F}$., the pulse was from 120 to 130 , and the respirations were 48 . There was very severe pain in the right side of the chest, referred especially to the axilla. There was marked orthopnoea (which persisted throughout his illness, he being compelled to maintain the sitting posture almost constantly). He was very tender in the right axilla especially, but no crepitus was felt. There was limited subcutaneous surgical emphysema felt in the right side of the neck, not extending below the right clavicle in front, nor quite to the upper level of the scapula behind, nor beyond the middle line in front. The respiratory movement of the right side of the chest was very poor. He was coughing up a considerable amount of very blood-stained expectoration, the cough being frequent and distressing. The apex beat was visible in the fifth inter. space one inch outside the nipple line; the first sound was slightly murmurish in the apical area, otherwise the heart sounds were clear. On percussion the right side of the chest was found to be highly resonant, the upper level of the liver dulness being markedly lowered. There was a very marked diminution of breath sounds in the right side of the chest both anteriorly and posteriorly; the breath sounds were not amphoric, nor was there any metallic tinkling. Some adventitious sounds were heard and were considered to be due to crepitus from fractured ribs. There were some tenderness and swelling over the spines of the lower cervical vertebræ, but their position was normal. The urine was very high coloured, acid, of specific gravity 1022, with much albumin, and no blood. Urates were present. The examination made was as limited as possible owing to the patient being in so much distress. The diagnosis of rupture of the lung with pneumothorax was made.

The treatment was as follows. The patient's right side was strapped with Mead's plaster and his arm was bandaged loosely and supported in a sling so as not to hamper the movements of the chest. These measures afforded him great relief, though his cough remained exceedingly troublesome. A cough mixture containing some opium was given. His bowels were got freely open. He slept very badly throughout, sleep being only obtainable by the aid of morphine. The cough and orthopnoea and restlessness were present throughout, but the expectoration changed from nearly pure blood to a nearly rusty character, becoming very viscid and difficult to dislodge, so that during the last few days the doses of morphine were reduced to a minimum.

On the day after admission crackling crepitations were heard in the left axilla; these persisted. The stiffness of the neck disappeared completely after two or three days, and the patient became able after five or six days to move the arm much more freely, though never able to elevate it. An ecchymosis became obvious in the right loin about six or seven days after admission.

On August 13th the chest was explored and almost pure blood containing no air was obtained. The respirations reached 70 on this day and the temperature varied from $98.2^{\circ}$ to $101^{\circ}$. It was considered inadvisable to aspirate in case of hæmorrhage recommencing. On the 16th the chest was again explored and then aspirated in the hope of relieving the distressing dyspnoea; only a few drachms of blood-stained fluid and a good deal of air were obtained. This procedure made no difference to the position of the apex beat and apparently did little good; it necessitated the removal of the strapping, which was not replaced. On this day the urine was examined and was found to be free from albumin. On the 17th the surgical emphysema was almost gone and was not observed at all on the 18th. The temperature from the 17th remained subnormal, the pulse became very feeble though less rapid, and on the 19th slight delirium was noticed. Pain below the right clavicle was very troublesome for the two days preceding his death, otherwise the patient was much easier than on admission. He at no time exhibited much cyanosis, so that no occasion arose for the performance of venesection. Respiration was always laboured, but the rate varied from 70 to 50 to 28 at different times. He died quietly at 12.15 A.M. on August 20th.

A post-mortem examination was performed. An incision was made on to the head of the right humerus, which was found in the normal situation and without fracture. There was a small bony mass in one tendon near its insertion into the humerus, which must have caused the crepitus felt. On opening the right pleura air escaped from it with a rush. A small amount (about eight ounces or so) of slightly bloodstained fluid was found in the right pleura (being possibly the serum of the clotted blood). There was a large amount of clot adherent to the lung surface and to the parietal pleura; this clot gave one the impression of having air in it. The right lung itself was small, collapsed, fleshy, airless, with a tear of the middle lobe. There was no abnormal inflammation. The left lung was resonant, but blood had evidently been inspired into it, for a frothy bloody fluid escaped on section. There was a remarkable absence of compensatory emphysema, the lung being only of about normal volume. There was an old fibroid tuberculous patch at the apex of the left upper lobe. There was no evidence of pneumonia. The pericardium contained a very small amount of clear fluid. The heart showed some flabbiness of the night ventricle, 
but was otherwise healthy with clean valves. The aorta showed one or two tiny patches of atheroma near the aortic valves. The liver was large and friable. The spleen was soft. The kidneys showed rather adherent capsules, especially the right one, with stellate veins, striate cortices, and ill-defined pyramids; they were very red and tough but there were no granulations. There was no sign of injury to the kidneys from the accident. The appendix was long, thin, curved, and bound down in nearly all its length ; there were several fine band-like adhesions holding it near its tip. The second, third, fourth, and fifth ribs were fractured at about 1 inch to $1_{\frac{1}{2}}$ inches from the costo-chondral junction; they showed no displacement. The sixth and seventh ribs were fractured about $1 \frac{1}{2}$ inches from the side of the spinal column; they had evidently been displaceable into the chest and may have been responsible for the tear in the lung. The first and other ribs escaped fracture. The skull and brain were not examined.

I Muttaburra, Queensland.

\section{THE PATHOGENESIS OF TABES DORSALIS.}

BY TOM A. WILLTAMS, M.B., C.M. EDIN.

CONTROVERSY as to the pathogeny of tabes has not ceased since Duchenne ${ }^{1}$ surmised its sympathetic origin and Charcot $^{2}$ later supposed it to be a posterior column dystrophy, similar to that of Friedreich's ataxia. His great authority prevented due attention to the researches of Obersteiner and his followers until the memoir of Redlich appeared in 1896. ${ }^{3}$ The discoveries as to the syphilitic etiology of tabes caused greater attention to the work of Nageotte, ${ }^{4}$ who in 1894 had indicated the constancy of lesions on the radicular nerve at the point where it receives its meningeal sheaths. These lesions correspond to one or other stages of the granulomatous process, varying as they do from simple round-cell infiltration to granuloma, and even breaking down with formation of cavities. They are due to primary chronic meningitis, evidenced by the lymphocytosis found by spinal puncture during life and post mortem when skilfully looked for, although the tendency of the process to resolution and fibrous-tissue formation leaves only a slight thickening in the membrane, already fibrous by nature.

The changes in the cord are consecutive to this. That this is so is proved by similar changes of the posterior column after disease of, or experimental section of, individual roots ${ }^{5}$ and by the changes occurring in the mechanical affection of the radicular nerves due to the increased intraspinal pressure caused by the growth of cerebral tumours. ${ }^{6}$ The noxa falls upon the root fasciculi very disparately ${ }^{7}$ and this corresponds to the disparate nature of the sensory troubles, which do not preponderate so much as formerly supposed upon the fibres which subserve the sense of attitudes and of muscular movement ; for it is now definitely shown that cutaneous sensations are always involved more or less, though probably later in the disease. ${ }^{8}$ The superficial lightning pains described by Gowers ${ }^{9}$ and the psychometric analysis of the sensibility of tabetics by Vaschide ${ }^{10}$ are an index to this, while the researches of Head ${ }^{11}$ enable us to explain the modifications in terms of deep, protopathic, and epicritic sensibility. The fibres subserving the life of internal relation may differ morphologically from those subserving external relationship as contended by Pierre Bonnier ${ }^{12}$ with particular reference to the eighth nerre, the principal posterior root, where the cochlear portion whose function concerns the outside world is

\section{Duchenne: Archives de Médecine, 1858.}

2 Charcot: Lecons Cliniques, 1888 .

3 Redlich: Centralblatt fuir Allgemeine und Pathologische Anatomie, 1896 , p. 985 .

4 Nageotte: Pathologie de Tabes Dorsalis, Paris, C. Naud, 1903 and

5 Koster: Zur Physiologie der Spinal-Ganglionen in der troph.

Nervösen Pathologie der Tabes, Leipsic, Engleman, 1904

${ }^{6}$ Le Cjonne : L'Enocephale, March, 1907

8 Déjerine: Sémiologie du Système Nerveux, Traité de Pathologie Générale de Bouchard et Brissaud.

9 Gowers : The Paing of Tabes, Brit. Med. Jour., 1906

10 Vaschide: Ktude Psychologique de la Sensibilité dans le Tabes, Académie des Sciences, Paris, 1902 .

II Head, Rivers, and Sherren: Brain, 1907, The Afferent Nervous System from a New Aspect.

12 Bonnier: Le Vertige, Paris, 1904; Le Tabes Laby rinthique, Nouvelle Iconographie de la Salpêtrière, 1899. affected only rarely, while the vestibular portion is concerned with intrinsic relationships and is involved very commonly indeed in the tabetic process. However this may be, it is certain that impaired sense of attitudes is always accompanied by impairment of the deep pain sense and of perception of the vibrations of the tuning fork by the bones, ${ }^{13}$ and as these functions are conveyed in the same peripheral path while they are separated within the cord ${ }^{14}$ clinical evidence is in entire harmony with the pathogenetic theory advanced by Nageotte. The data furnished by the optic nerve symptoms are similarly best explicable by a meningeal affection, involving in this case not a posterior root but a homologue of an intraspinal path. ${ }^{15}$

The tabetic symptoms referable to the sympathetic do not differ from those produced by experimental section of the spinal roots, nor from those in syringomyelia, which, however, attacks the cell bodies in the intermedio-lateral column. ${ }^{16}$ Charcot's negation of changes in the sympathetic is effectively disproved by the researches of Roux, ${ }^{17}$ who found the medullated fibres markedly decreased in tabetics. The anterior roots are not unaffected, but the relative absence of serious myopathies early in the disease is accounted for by the rapid regeneration of the fibres. This is shown by the "terminaisons en croissance" exhibited by Nageotte's ${ }^{18}$ preparations and by the results of section experiments. ${ }^{19}$ The regeneration of the posterior root fibres extends only to Redlich's ring at which they lose the neurilemma sheath. ${ }^{20}$ Finally, evanescent lymphocytosis and reflex iridoplegia, the two most characteristic signs of tabes, are found in many cases of syphilis without other tabetic symptoms ${ }^{21}$; indeed, both sometimes occur in the secondary stage, the former in as many as 40 per cent. ${ }^{22}$ The contention of Babinski and Nageotte ${ }^{23}$ is therefore accepted that a chronic syphilitic meningitis is responsible for what has been called tabes dorsalis and that it was formerly disregarded on account of the tendency to the occurrence of resolution and fibrosis of the lesions.

The practical application of this conclusion may be of the greatest importance in the treatment of the disease. Cases taken early may be completely arrested, ${ }^{24}$ and in all cases the active manifestations may be resolved if adequately treated before the destruction of the noble elements has occurred, though naturally the residues of former exacerbations cannot be removed.

Washington, D.C., U.S.A.

\section{A MODIFICATION OF THE ROMANOWSKY STAIN.}

\section{BY F. H. JOS EPH,} ASSISTANT BACTERTOLOGIST.

(From the Government Laboratories, Johannesburg, South Africa.)

THE following quick and simple method of preparing an eosin-methylene blue compound stain gives excellent results. The appearances of blood films stained by this method are similar to those coloured by Leishman's stain, although the blue and violet tints are a little different and the red is deeper. The nuclear structure is particularly sharply defined and the granules of the various leucocytes are well shown. The stain has now been in constant use in these laboratories for 18 months, and in our hands has given better and more uniform results than Leishman's stain.

Solution I., Poiyohrome methylene blue.-Dissolve 1 gramme of Grubler's ordinary methylene blue in 100 cubie centimetres of distilled water. After 24 hours decant the supernatant fluid, and to 90 cubic centimetres add 10 cubic centimetres of a 1 per cent. aqueous solution of sodium

13 Marinesco : Semaine Médieale, 1905, vol. xxv., p. 565.

14 Head: Brain, 1906, Grouping of Afferent Impulses withio the Cord

15 Marie et Leri : Revue Neurologique, 1905.

16 Bruce: Review of Neurology and Psychiatry, The Intermediolateral Tract, 1907, p. 1.

$$
\text { 17 Roux : Thèse de Paris, } 1900 .
$$

18 Nageotte: Société de Biologie, 1906

19 Bickles: Neurologisches Centralblatt, No. 20, 1907. 20 Orr apd Rows : Brain, 1904.

21 Babinski : Revue Neurologique, 1901.

22 Ravaut et Beletre: Société Médícale des Hôpitaux de Paris, 1901.

23 Babinski et Nageotte: Société de Biologie, 1905 